\title{
Coronary Artery Connection. Cone Trunk Sharks Varieties Anatomy Study (Selachians)
}

\author{
Conexión de la Arteria Coronaria. Estudio de las \\ Variedades Anatómicas del Cono Tronco en Tiburones (Selachians)
}

\author{
J. C. Saba \& J. C. Prates
}

SABA, J. C. \& PRATES, J. C. Coronary artery connection. Cone trunk sharks varieties anatomy study (Selachians). Int. J. Morphol., 27(4):1201-1207, 2009.

SUMMARY: Due to our interest in clarifying the congenic problems at the origin of the coronary arteries, we have published in the early 70's a theory (Borges et al., 1974) in which the coronary arteries would be the last pair of aortic arches that, at the beginning of the embryogenesis, would be connected with the previous arch, trunk of the lung's artery through a duct which we named "ductus coronarius".

KEY WORDS: Selachian; Coronary Arteries.

\section{INTRODUCTION}

Throughout the study of both fish aortic and branchial arches, Parrot (1958) mentioned the existence of sharks holding 7 gills (Heptranchias Type). This shark has been described by Bonaterre in 1788 (Florida museum of Natural History, 2009) and several varieties are still found in midtemperature seas regions (Fig. 1).

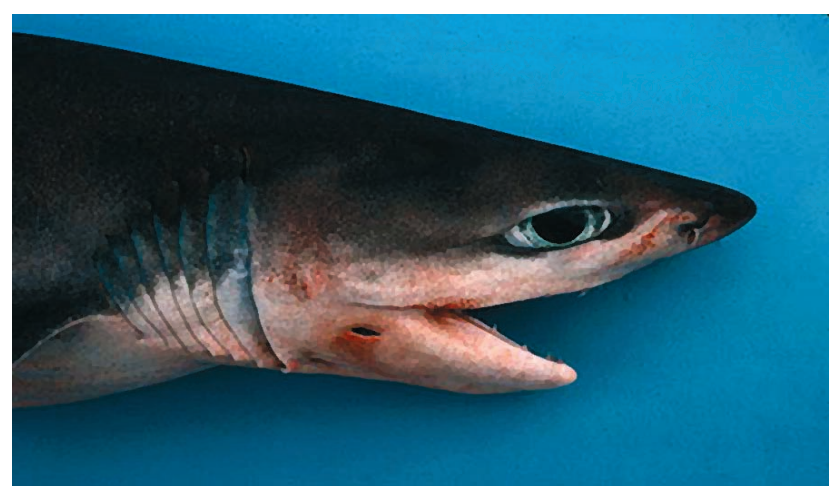

Fig. 1. Photo obtained at the Florida Museum of Natural History Ichthyology Department Website. Heptranchias Perlo Shark. Order Hexanchiformes, Family Hexanchidae, Race Gender Heptranchias, Species Perlo

This opinion was in disagreement with the embryologic and cardiologic classic studies on aortic arches, which were based on the fact that they would always be constituted of 6 (Congdon, 1922) pairs of arches. So far, in human beings, there is a standard configuration of the aortic arches, consisting of 6 (De Andrés et al., 1993) pairs, being the hypothetic 5th pair used as a true "corollary."

Theories on the coronary embryology. The development of the coronary vessels as described by Wada et al. (2003) is a vasculogenesis example followed by the angiogenesis with the original variables, specific to heart development. The Vasculogenesis has been described as the new blood vessels generation, since the angiogenesis could be defined as the generation of capillar vessels, veins and arteries from the pre-existing blood vessels. The process is initiated through the carrying of vasculogenic type cells to the surface of heart, after heart has started beating. These cells should be then scattered through all the heart; being differentiated as endothelial cells, plain muscular cells and fibroblasts; which will subsequently form veins, capillar vessels and arteries which will further be connected to the aorta sinus.

Coronary system connection to aorta. Bogers et al. (1988, 1989) mentioned this as a fascinating item, in an attempt to define how the coronary arteries would be connected to aorta, and the reason why same would be placed at the center 
of aortic valve branches. It was interesting to further notice that when these anomalies occurred, same were always in circle and never straight lined. It was then concluded that the explanation on cells and molecular regulation of this process would be mandatory for the understanding of the structure of coronary vessels connection with aorta. So far, the coronary vessels connection to aorta continues to be based on assumptions.

Study on coronary arteries embryology in "Selachians". De Andrés et al. (1993), at the Department of Animal Biology, Faculty of Science, University of Malaga, (Spain), prepared in 1993 a study on the coronary vessels development in sharks embryos (Scyliorhinus canícula) and concluded that the primary evidences of heart vessels occurred with $31 \mathrm{~mm}$ length embryos which was then defined as the existence of a diverticulum in the venous sein. This diverticulum when being developed originated the coronary sinus. The arterial coronary vessels appeared at the $40 \mathrm{~mm}$ embryos where two arteries were coming from the hypobranchial artery, and splitted in four coronary arteries which descended through the cone trunk. With embryos over $50 \mathrm{~mm}$, it could be easily observed the course of coronary arteries of hypobranchial arteries to the "conoventricular" sulcus. As to $58 \mathrm{~mm}$ length embryos, the coronary arteries were totally developed since sharks birth occurs when they have 72 to $76 \mathrm{~mm}$ length.

Shark's coronary anatomy. De Andrés et al. (1990, 1992) in a publication on coronary sytrunk anatomy study of 5 types of sharks, proved a high grade of uniformity of coronary standards of most types.

In all types, conoray arteries were coming from the last hypobranchial arteries and descending through the cone trunk.

The standardization was primarily based on the conal coronary trunk position, its origin, trajectory and importance related to the ventricular branches.

In this current description, two different coronary arteries standards have been defined for sharks:

1. Lateral coronary Trunks Standards. In this case, two lateral coronary trunks are present, the right and left sides, with origin of hypobranchial arteries. Both right and left coronary trunks produce several ventricular branches, namely ventral and dorsal branches (Fig. 2).

2. Dorsoventral coronary trunk standard. Defined by Grant as typical of elasmobranchii, is formed by two hypobranchial arteries (Grant, 1926; Grant \& Reignier, 1926). From these vessels two coronary trunks are produced - dorsal and ventral - and they run respectively above and below the "conus arteriosus". For a better understanding of the coronary

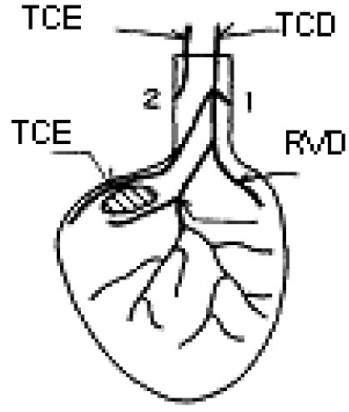

Hexanchus griseus

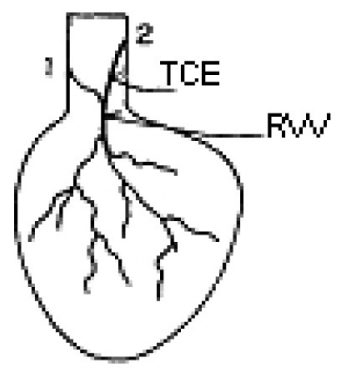

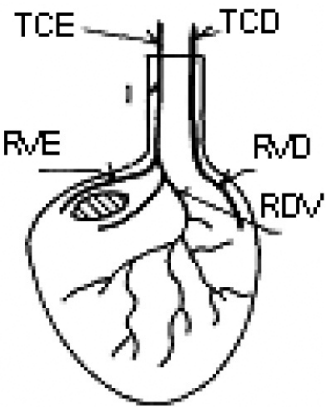

Heptranchios perlo

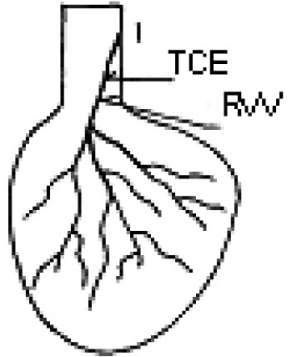

Fig. 2. Diagram of coronary arteries standards in hexanchiformes. The ventral surface is irrigated by left coronary trunk branches. RDV. Dorsal ventral branch; RVE. Left Ventricular branch; TCD Right Coronary Trunk; TCE. Left Coronary Trunk; RVD - Right Ventricular Branch; RVV. Ventral ventricular branch

arteries relationship with the hypobranchial arteries (last pair of arches) and with the cone trunk, we have tried to study, through contrast injections, the (aortical) branchial arches of sharks bearing 5 gills. Hence, we based ourselves in previous studies that, in these primitive vertebrates, the coronary arteries, both gnatic and cephalic, were originated from the efferent branches of branchial trunks. Due to the close connection with the arterial cefalic branches, ventral and dorsal aorta, phylogenetically, we might admit that, in human beings, coronary malformation births could be related to any aortic arch.

The aim was to study the relation of coronary arteries with cone trunk and with branchial arches through hypobranchial arteries in sharks.

\section{MATERIAL AND METHOD}

Sixteen types of several types of "Selachians" were used, fished in the city of Itanhaem - State of São Paulo Brazil, and all types had five gills. After the capture by 
professional fishermen (Sudepe), sharks have been cut at the liver level and the head portions have been refrigerated and sent to Hospital São Paulo - Escola Paulista de Medicina, Radiology Department.

Since only the Shark's heads have been received, it was difficult to precisely define, types classification. Based on sharks photographs obtained through consultation of Projeto Cação (Câmpus Experimental do Litoral Paulista, 2009) which, through biologic material collection and processing, defined the elasmibranchii types more frequently found at littoral of the state of São Paulo, we have defined the sixteen types (Table I).

Table I. Definition of the different the sixteen types of sharks.

\begin{tabular}{lllc}
\hline Order & Family & Class & Number \\
\hline Lamniformes & Odontaspididae & Carcharia & 3 \\
Squaliformes & Squalidae & Squalus & 3 \\
Carcharhiniformes & Sphymidae & Sphyrna & 5 \\
Carcharhiniformes & Carcharhinidae & Carcharhinus & 4 \\
Carcharhiniformes & Triakidae & Mustelu & 1 \\
\hline
\end{tabular}

We have not been concerned about the accurate exactitude of types definition, due to De Andrés et al. (1993) conclusions, which classified all types as having a high grade of coronary uniform standard (Fig. 3).

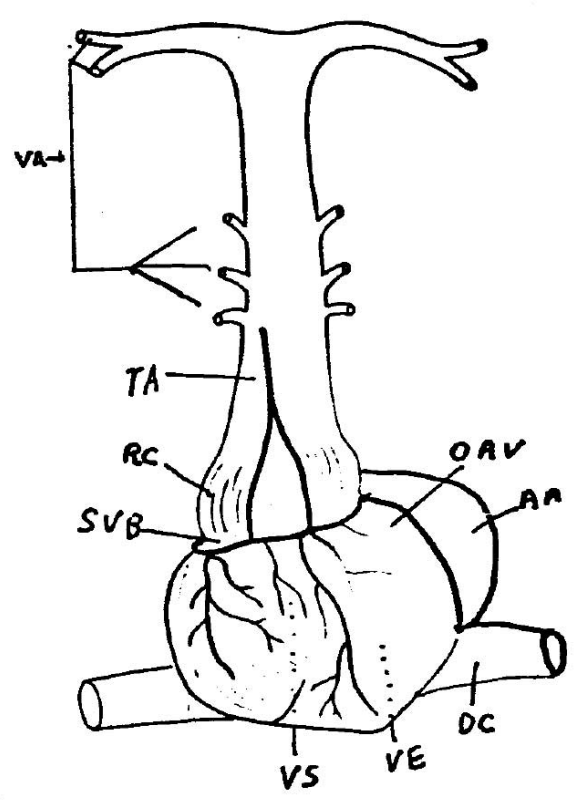

Fig 3. Studied Shark Heart Plan and ventral aorta. DC. Cuvier Ductus; AA. Single Atrium; OAV. Atrium Ventricular Hole constituted of 2 Large valves, front and back, and 2 Small valves, D. and E.; VE.Ventriculum, entrance; VS.Ventrículum, exit; SVB. Ventricular Bulbiferous Channel; RC. "conal” Region; TA. Arterial Trunk or ventral aorta; VA. Afferent vessels.
Both ventral and dorsal aorta and coronary arteries and lateral coronaries should be studied according to their aspect. Variable quantities of contrast were injected through No. 8 Lehmann catheters (Fluopac 71\%), into ventral aorta, at the normal back-flow direction, performing radiographic studies of the different picture contrast stages. Through those various injections we tried to verify the presence or absence of coronary ostium close to aortic valve, aortic valvar capacity, number and configuration of branchial branches whether afferent or proximal, efferent or distal.

Due to the contrast spillover through the gills when it flew through afferent arteries, the black flow injection took place through the coronary arteries, for a better analysis of efferent arteries. Lehmann catheter had been used due of the inexistence of side holes but one single distal hole, thus enabling the injection of contrast into arteries with a diameter similar to the catheter's. Through the injection of $10 \mathrm{ml}$ retrogressing contrast into the coronary prior and back arteries, we have managed to give opacity to the arteries and all the branchial arches both to right through the back coronary, and the left through the front coronary.

\section{RESULTS}

Figs. 4 and 5 show the configuration of afferent or proximal vessels, with respective origin at ventral aorta. Despite the 16 analyzed sharks bear 5 gills, there were afferent trunks fusions reducing their quantity from 3 to 4 afferent branches. Through the contrast injections in ventral aorta we were unable to visualize the efferent branches due to contrast spillover externally through the gills. Over all injections in ventral aorta the efficiency of the aortic valve has been verified and ostium presence of coronary arteries filling has not been visualized.

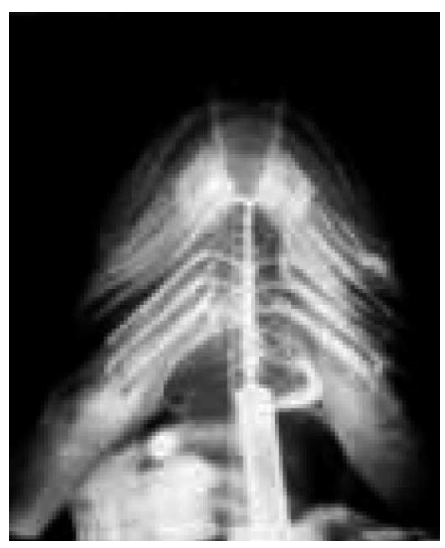

Fig. 4. Contrast injected in a Five gills shark ventral aorta, showing four efferent vessels and since the former is splitted in two, each going to a different gill. 


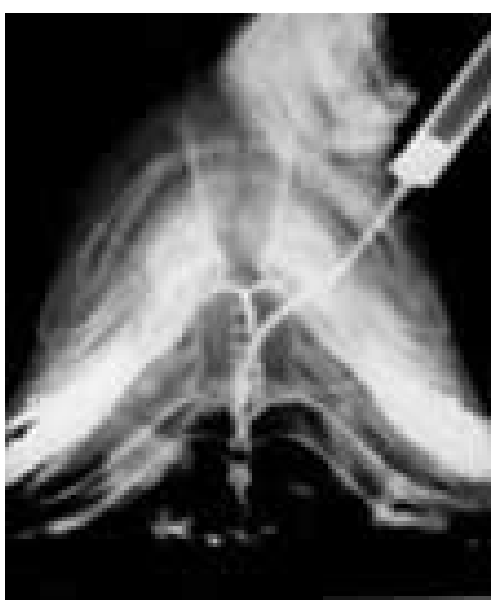

Fig. 5. Back flow injection in ventral aorta to verify aortic valve efficiency and the inexistence of coronary ostium.

In Fig. 6 we observe the efferent or distal vessels configuration through a back flow injection in the dorsal aorta. We should point out that each efferent vessel is formed by two branches, only located at the superior gill margin and the other one at the inferior margin of the superior gill. This is why from 5 gills, only 4 efferent arterial branches are formed.

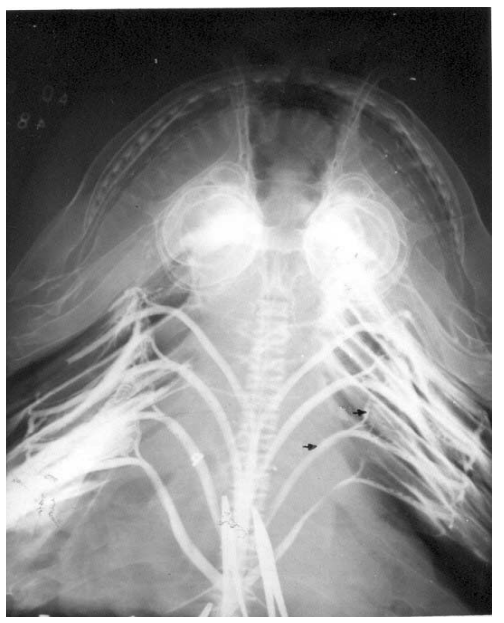

Fig. 6. Contrast injection back flow in dorsal aorta. The 4 efferent or distal vessels forming dorsal aorta are visualized. Each efferent vessel is constituted of a thick branch (A) that flows at the superior side of the gill and a thinner one which flows upwards to connect with the anterior efferent, behaving as a "ductus" (D). See figures 7 and 13

The contrast back flow injections in coronary arteries, demonstrated the following aspects:

Back Coronary - With a higher caliber than front coronary, it could be more easily characterized. Figures 8 through 11, show the aspects of injections with little contrast, visualizing the initial part of the back coronary flowing to the cephalic part, receiving several collateral vessels from right side gills (epibranchial and endobranchial arteries), following the contrast up to the specimen cephalic part, where the artery gets full and goes to the skull basis and the right side jaw.
Increasing the contrast we managed to fill the right side gill efferent branches. The midriff arteries had to be previously gripped to prevent spilling of the contrast at the place where the shark had been cut, since its origin was the same arterial trunk which formed the coronary arteries.

Front coronary artery: We found the same aspects as back coronary, however having noticed that the injections into the front coronary made contrast of the left side gills. We have also observed the filling of the artery of left side jaw and the skull base artery (Fig. 12). In figs. 8, 9, 10 and 11, we have observed back flow contrast injection of back or dorsal coronary (A).

Afferent vessels coming out ventral aorta and the fusion of afferent trunks, have their number reduced from 5 to 4 branchial branches. Studying the efferent or distal vessels configuration, through an injection into dorsal aorta, we might verify that each efferent vessel was formed by two branches, one in the gill superior margin and the other in the gill inferior margin, and from 5 gills 4 efferent branches are formed.

It was possible to evaluate the anatomy of coronary arteries, as well as the presence of collateral blood circulation, but in the several types of selachians observed, we have not noticed significant anatomic differences related to the coronary standard.

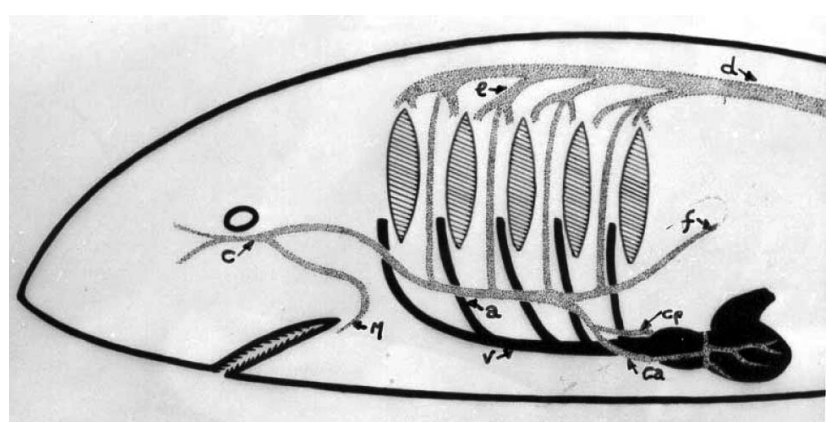

Fig. 7. Sharks' blood system. From the heart located at the ventral part comes the ventral aorta (v), and from the latter come the afferent vessels (a)which bring the venous blood to the gills from where leave the efferent vessels (e) to form dorsal aorta (d) that supplies arterial blood to the fish tail. The cephalic portions receive arterial blood through epi and endobrachial vessels which come from efferent vessels and return to the ventral aorta area, forming a vase of longitudinal direction that gives birth to the head arterial branches (c) and for the jaw $(\mathrm{m})$. This same vessel supplies branches to form the phrenic arteries (f) and both back(cp) and prior (ca) coronaries. 


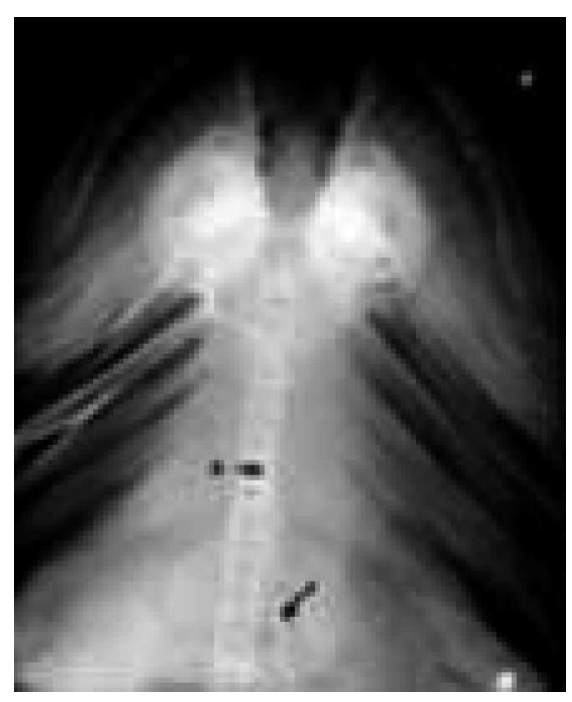
we observe the filling of Vessel (A) going in the direction of the cephalic region, formed of branches coming from both sides, being the higher carrying the contrast up to the right side first gill and the other to the cefallic area and beginning of the artery of the jaw (M).

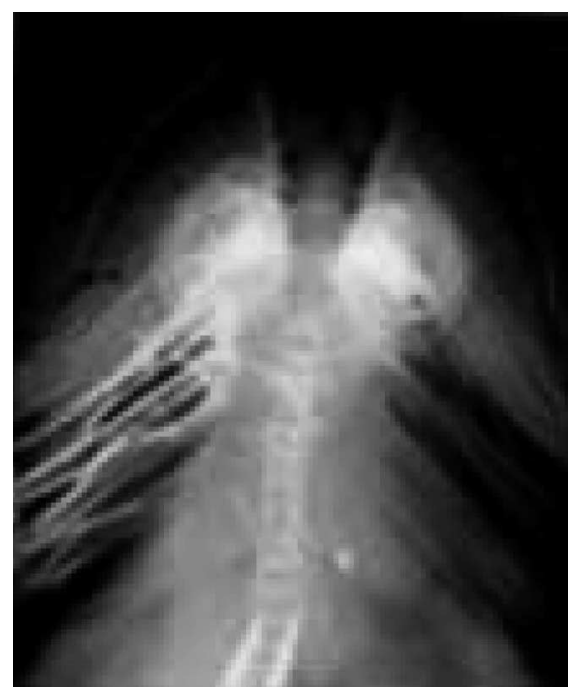

Fig. 9 - With a contrast of $8 \mathrm{~cm}^{3}$ we were able to fill efferent branches

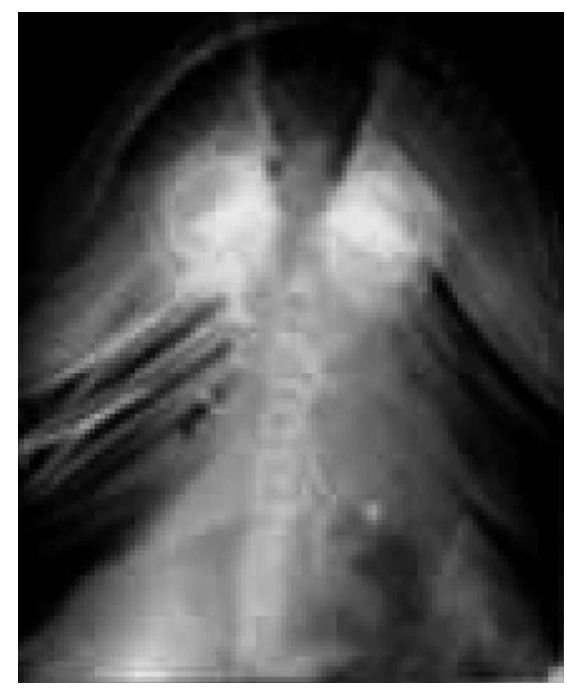

Fig. 10 - With a contrast of $18 \mathrm{Cm} /{ }^{3}$ the jaw artery $(\mathrm{M})$ is complete and the contrast practically goes over the gills

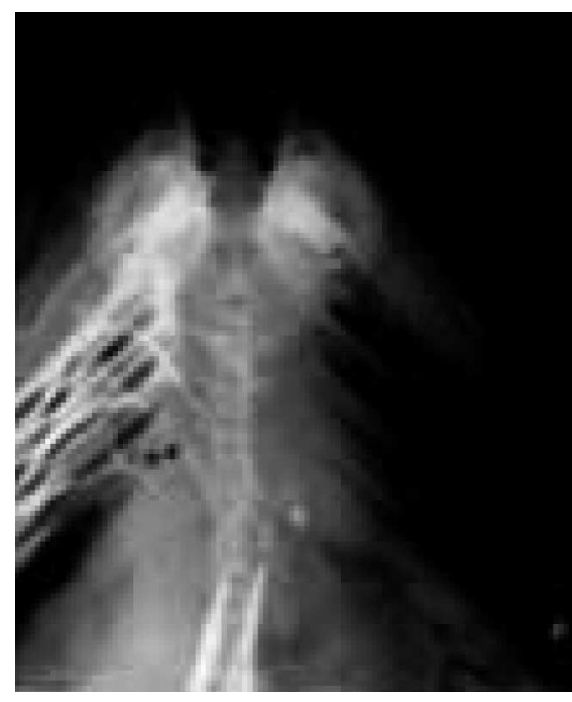

Fig. 11 - All the right side efferent vessels (E) are under contrast and through these arteries are filled (F) going to the tail area (Phrenic type)

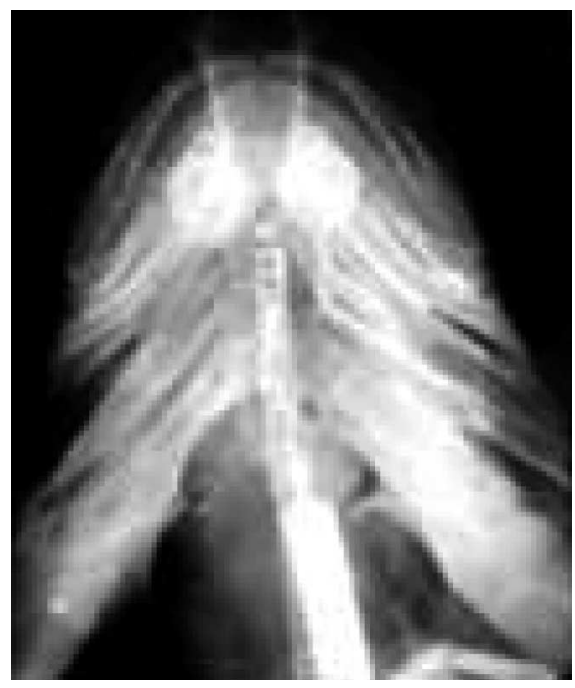

Fig. 12 - The back flow contrast injection in front or ventral coronary artery. This artery is thinner than the back artery and the introduction of catheters is difficult. Thus the injections have been made with a very thin needle. The vessels are similar to the back artery's injections, being now filled the vessel epi...

\section{DISCUSSION}

We have performed our studies using Selachians, since their heart is similar to the human heart with 5-6 weeks of uterine life. The heart has a tubular shape and is constituted of 4 consecutive chambers. The venous sinus is formed of two Cuvier ducts, one atrium, one ventricle from which comes out a muscle bulb, followed by formation of the aorta artery. The aortic valves are located at the beginning of ventral aorta (De Andrés et al., 1990). Thus the entire heart uses only venous blood.

Our findings in sharks do not support the previously formed theory, when we thought that the coronary arteries would be the last pair of aortic arches, but we concluded 


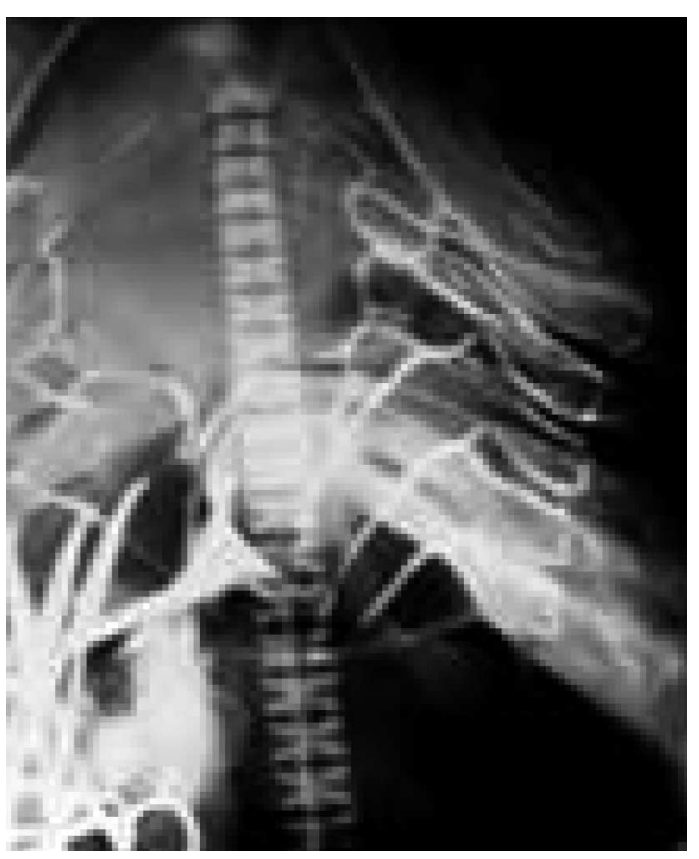

that there is a clear connection between the coronary arteries and the branchial arches. Further, in human beings, we were not able to find coronary vessels connection with the descending part of aorta artery in order to classify them as aortic arches.

In both human beings and animals, studies are not conclusive as to the way and exact timing of coronary arteries connection with the cone trunk after its splitting phase (Wada et al.).

In hearts with hipoplasic aorta, coronary ostiums are hipoplasic while coronary arteries have normal diameter and anatomy. Would both coronary arteries and ostiums bear the same embryologic origin?

We still have not explained the reasons why the arteries, when coming off the lungs artery, do not mandatorily connect with lungs artery valve sinus, but in most cases (Wilkins et al., 1988) with the lungs artery trunk, well above valvar level and considered as the proximal portion of the sixth aortic arch.

Finally, there is not a suitable explanation, through current embryological theories, to the case described by Angelini (2005) which in a two month old child, both coronary arteries come out of the lungs' artery trunk, with different ostiums.

In conclusion our findings in sharks do not support the previously stated hypothesis, which the coronary arteries would be the last pair of aortic arches, but they show that there is a clear connection between the coronary arteries and the branchial arches.

In sharks, which the rising part of aorta only contains venous blood, there is no connection between the coronary vessels and the aorta valvar sinus, denying the currently accepted embryological theories.

As to the selachians, the back and front coronary arteries are the extension of their respective longitudinal trunks, coming out of the efferent arterial branches from the branchial aortic branches. From the main trunk also come out the jaw, strapedial, hyoideous and phrenic arteries.

The formation of the back coronary artery in Selachians prevail the efferent branches of right side antimer while for the front coronary artery, the branches of left side antimer are predominant.

In selachians, the efferent branches are predominant at the right side of formation of the back coronary artery and for the left side in the formation of the front coronary artery being the gauge of the latter inferior to the formers. Therefore, both would be in close connection with the aortic (branchial) arches and carry oxygen blood to the myocardium.

In vertebrates, we might phylogenetically admit that coronary arteries can be connected to any branch of the aortic arches. 
SABA, J. C. \& PRATES, J. C. Conexión de la arteria coronaria. Estudio de las ariedades anatómicas del cono tronco en tiburones (Selachians). Int. J. Morphol., 27(4):1201-1207, 2009.

RESUMEN: Debido a nuestro interés en aclarar los problemas congénicos en el origen de las arterias coronarias, hemos publicado a principios de los años 70 una teoría (Borges et al., 1974) en que las arterias coronarias serían el último par de arcos aórticos que, en el comienzo de la embriogénesis, estarían conectadas con el arco anterior, tronco de la arteria pulmonar a través de un conducto que hemos llamado "conducto coronario".

\section{PALABRAS CLAVE: Selácio; Arterias coronarias.}

\section{REFERENCES}

Angelini, P. The miraculous survival of an exceptional baby: can a heart manage to function with anomalous origin of both coronary arteries from the pulmonary artery? Tex. Heart Inst. J., 32(3):351-3, 2005.

Bogers, A. J. J. C.; Gittenberger-De Groot, A. C.; Dubbeldam, J. A. \& Huysmans, H. A. The inadequacy of existing theories on development of the proximal coronary arteries and their connexions with the arterial trunks. Int. J. Cardiol., 20(1):117-23, 1988 .

Bogers, A. J. J. C.; Gittenberger-De Groot, A. C.; Dubbeldam, J. A. \& Huysmans, H. A. Scanning electron microscopy substantiates histology in showing the inadequacy of the existing theories on the development of the proximal coronary arteries and their connections with the arterial trunks. Acta Morphol. Neerl. Scand., 26(4):225-37, 1989.

Borges, S. J. P.; Saba, J. C.; Hayashi, H. Artérias Coronárias, o último par de arcos aórticos (Ductus Coronarius). Arq. Bras. Cardiol., 27:107, 1974.

Câmpus Experimental do Litoral Paulista. Espécies de Elasmobrânquios encontradas em Itanhaém no âmbito do Projeto Cação. UNESP - Universidade Estadual Paulista "Júlio de Mesquita Filho". Avalaible in: http:// www.csv.unesp.br, 2009.

Congdon, E. D. Transformation of the aortic arch system during the development of the human embryo. Contrib. Embryol., 14:47, 1922.

De Andrés, A. V.; Muñoz-Chápuli, R. \& Sans-Coma, V. Development of the Coronary Arteries and Cardiac Veins in the Dogfish (Scyliorhinus canicula). Anat. Rec., 235(3):436-42, 1993.

De Andrés, A. V.; Muñoz-Chápuli, R.; Sans-Coma, V. \& GarciaGarrido, L. Anatomical studies of the coronary system in elasmobranchs: I. Coronary arteries in lamnoid sharks. Am. J. Anat., 187(3):303-10, 1990.
De Andrés, A. V.; Muñoz-Chápuli, R.; Sans-Coma, V. \& GarciaGarrido, L. Anatomical studies of the coronary system in elasmobranchs: II. Coronary arteries in hexanchoid, squaloid, and carcharhinoid sharks. Anat. Rec., 233(3):42939, 1992.

Florida museum of Natural History. Avalaible in: www.flmnh.ufl.edu/fish/Gallery/Descript/SnoseSgillShark/ SnoseSgillShark.html, 2009.

Grant, R. T. Development of the cardiac coronary vessels in the rabbit. Heart, 13:261, 1926.

Grant, R. T. \& Reignier, M. The comparative anatomy of the cardiac coronary vessels. Heart, 13:285-317, 1926.

Parrot, A. W. Big Game Fishes and Sharks of New Zealand. London, Hodder and Soughton, 1958.

Wada, A. M.; Willet, S. G. \& Bader, D. Coronary vessel development: a unique form of vasculogenesis. Arterioscler. Thromb. Vasc. Biol., 23(12):2138-45, 2003.

Wilkins, C. E.; Betancourt, B.; Mathur, V. S.; Massumi, A.; de Castro, C. M.; Garcia, E. \& Hall, R. J. Coronary artery anomalies: a review of more than 10.000 patients from the Clayton Cardiovascular Laboratories. Tex. Heart. Inst. J., 15:166-73, 1988.

Correspondence to:

J. C. Saba

Department of Morphology and Genetic

Federal University of São Paulo

Rua Botucatu 740, CEP 04023-900

SP - BRAZIL

E-mail: joao.chaker@terra.com.br

Received: 14-04-2009

Accepted: 24-09-2009 
